Research Article

\title{
The Relieving Effects of a Polyherb-Based Dietary Supplement ColonVita on Gastrointestinal Quality of Life Index (GIQLI) in Older Adults with Chronic Gastrointestinal Symptoms Are Influenced by Age and Cardiovascular Disease: A 12-Week Randomized Placebo-Controlled Trial
}

\author{
Gang Xu, ${ }^{1}$ Guoqiang Xing $\mathbb{D}^{2,3}{ }^{2,3}$ Bing Zhang, ${ }^{2}$ Jingfen Zhu $\mathbb{D}^{1},{ }^{1}$ Yong Cai, ${ }^{1}$ Tian Shen, \\ Jianyu Rao, ${ }^{4}$ Rong Shi, ${ }^{5}$ Zhaochun Cao, $^{6}$ and Tuong Nguyen ${ }^{7}$ \\ ${ }^{1}$ Department of Community Health and Behavioral Medicine, School of Public Health, \\ Shanghai Jiao Tong University School of Medicine, Shanghai 200025, China \\ ${ }^{2}$ The Affiliated Hospital and the Second Clinical Medical College of North Sichuan Medical University, \\ Nanchong Central Hospital, Nanchong 637000, China \\ ${ }^{3}$ Lotus Biotech.com LLC, John Hopkins University-MCC, 9601 Medical Center Drive, Rockville 20850, Maryland, USA \\ ${ }^{4}$ Department of Pathology and Laboratory Medicine, David Geffen School of Medicine, University of California at Los Angeles, \\ Los Angeles 90095, California, USA \\ ${ }^{5}$ School of Public Health, Shanghai University of Traditional Chinese Medicine, Shanghai 201203, China \\ ${ }^{6}$ Jiaxing Subdistrict Community Health Service Center, Hongkou District, Shanghai 200086, China \\ ${ }^{7}$ Department of Research, DRM Resources, 1683 Sunflower Avenue, Costa Mesa, CA 92626, USA
}

Correspondence should be addressed to Guoqiang Xing; gxing99@yahoo.com and Jingfen Zhu; zhujingfenjt@163.com

Received 11 October 2020; Revised 16 July 2021; Accepted 17 August 2021; Published 10 September 2021

Academic Editor: Wan Mohd Aizat

Copyright (C) 2021 Gang Xu et al. This is an open access article distributed under the Creative Commons Attribution License, which permits unrestricted use, distribution, and reproduction in any medium, provided the original work is properly cited.

\footnotetext{
Chronic gastrointestinal symptoms (CGS) negatively affect the quality of life in about $15-30 \%$ of the population without effective drugs. Recent studies suggest that dietary supplement may improve CGS, but inconsistent results exist. The goal of this study is to evaluate the effect of a polyherbal-based supplement ColonVita on the gastrointestinal quality of life index (GIQLI) in 100 old adults with CGS (63.1 \pm 9.6 years) who were randomly assigned to daily ColonVita or placebo tablets ( $n=50 /$ group) for 12 weeks in a double-blind, randomized controlled trial design. No significant fibrdifferences were found between ColonVita and placebo in the baseline total GIQLI score $(101.12 \pm 16.87$ vs. $101.80 \pm 16.48)(P>0.05)$ or postintervention total GIQLI score $(114.78 \pm 9.62$ vs. $111.74 \pm 13.01)(P>0.05)$. However, ColonVita significantly improved 16 scores of the 19 core GI symptoms compared with 10 items improved by placebo. The ColonVita group significantly improved the remission rate of 5 core GI symptoms compared to placebo and significantly improved the total GIQLI scores $(118.09 \pm 7.88$ vs. $109.50 \pm 16.71)(P<0.05)$ and core GI symptom scores $(64.61 \pm 3.99$ vs. $60.00 \pm 8.65)(P<0.05)$ in people $\geq 60$ years of age $(n=49)$ but not in those under $60 \mathrm{y}(n=51)$. ColonVita significantly improved the total GIQLI scores and core GI symptom scores in people without cardiovascular diseases (CVD) $(n=56)(116.74 \pm 9.38$ vs. $110.10 \pm 14.28)(P<0.05)$ and $(63.11 \pm 4.53$ vs. $59.93 \pm 8.03)(P=0.07)$, respectively, but not in those with CVD $(n=44)$. Thus, ColonVita was beneficial for old adults with CGS, especially those $\geq 60$ years of age and without CVD. Because a heterogenous pathogenesis of CGS-like irritable bowel syndrome (IBS) and inflammatory bowel disease (ISD) is differentially associated with CVD, different comorbidities may have influenced the outcomes of different trials that should be controlled in further studies.
} 


\section{Introduction}

Chronic gastrointestinal symptoms (CGS) include a range of medical conditions from irritable bowel syndrome (IBS) to inflammatory bowel disease (IBD), ulcerative colitis (UC), and Crohn's disease (CD) that affect about $15-30 \%$ of the general population. The common symptoms of CGS include inflammation, postprandial abdominal pain, dyspepsia, abdominal distention (bloating), anorexia, heartburn, vomiting, constipation, and chronic diarrhea. The impact on the overall quality of life is the most significant complication of CGS [1].

CGS used to be more common in industrialized countries that have steadily increased since the middle of 20th century but remains low in developing countries [2]. However, by the turn of 21st century, CGS have become a global disease as more people in newly industrialized countries adapted to the life styles of the industrialized countries. A recent National Institutes of Health- (NIH-) sponsored National GI Survey shows that an estimated $61 \%$ of the US population had $\geq 1$ GI symptoms in the past week, with the heartburn/reflux (30.9\%), abdominal pain $(24.8 \%)$, bloating (20.6\%), diarrhea (20.2\%), and constipation $(19.7 \%)$ as the most common symptoms and nausea/vomiting (9.5\%), dysphagia (5.8\%), and bowel incontinence $(4.8 \%)$ as the less common symptoms [3]. According to US Center for Disease Control (CDC), there are more than 3 million US adults who had IBD in 2015, and the number is increasing each year. The cases of IBD in China has increased from 1047991 in 1990 , to 2665081 in 2017 , with a $2.9 \%$ annual percentage change (APC) $[2,4]$.

The pathogenesis mechanism of increased global CGS prevalence is complex and heterogenous. CGS may occur in young and old people due to changes in the intestinal microenvironment or weakened physiological function of the digestive and absorption systems [5]. The contract and relaxation of the muscles lining the intestines to move food along the digestive tract can also be weakened by venous thromboembolism (VTE) and ischemic colitis that result in intermittent abdominal pain/discomfort, altered bowel patterns, and abdominal bloating/distension [6].

Genetic, gender, and dietary may contribute to CGS. Psychological distress, anxiety, depression, and childhood adversity are risk factors of CGS. CGS may also occur due to changes in the intestinal microenvironment and inflammatory status induced by stress and dietary pattern changes associated with industrialization from plant-based fiber-rich diet to proinflammatory high animal fat diet, herbicide/ pesticides/antibiotics residuals in food, and genetically modified food or food preservatives that may inhibit or disrupt intestinal microbes, thus compromising the physiological function of the digestive and absorption systems $[4,5,7-9]$.

Dietary factors such as milk/milk products, wheat products, caffeine, and fried and smoked food may trigger CGS and VTE [10-20], which are strongly related to obesity, CGS, and cardiovascular diseases [21, 22] that can be controlled by adapting the Dietary Approaches to Stop Hypertension (DASH) diet that is rich in fruits, vegetables, and dairy protein but low in saturated and total fat [23-26].
Current opinion is that developing effective dietary intervention is more important than studying the etiology of CGS [27]. Although the FDA has approved multiple agents for treatment of CGS (laxatives as the anticonstipation agent; loperamide, diphenoxylate, and atropine as antidiarrheal agents; lubiprostone as a chloride channel activator for women with IBS constipation; alosetron hydrochloride as a serotonin 5-HT3 antagonist for women with severe diarrhea-predominant IBS; belladonna alkaloids/phenobarbital, hyoscyamine, dicyclomine, propantheline, and peppermint oil as antispasmodics for abdominal cramps and associated diarrhea; rifaximin as antibiotics for concurrent small bowel bacterial overgrowth; fluoxetine, citalopram, sertraline, desipramine, amitriptyline, venlafaxine, and duloxetine as antidepressants to relieve gut pain and psychological distress, anxiety, and depression) and for IBD (aminosalicylates, corticosteroids (prednisone), immunomodulators, and biologics), these agents do not cure CGS.

Recent studies suggest that dietary or herbal supplements may balance beneficial bacteria in the intestinal track, ease bowel movement, and prevent constipation of IBS [10-12, 28, 29]. Coadministration of multiple medicinal herbs is a common practice in traditional Chinese medicine for multitargeting and for improving bioavailability and efficacy of the therapeutic ingredients. ColonVita is a dietary supplement consisted of the blend of Aloe extract, acai tropical fruit extract, citrus bioflavonoids, peppermint leaves extract, magnesium hydroxide, and vitamin C. ColonVita has been used in America and other countries for more than ten years at the time of this study due to its potential properties of nourishing, relieving, lubrication of the gastrointestinal system, stimulating intestinal neural peristalsis, softening the feces, stimulating hepatic secretion of detoxifying enzymes, and controlling Helicobacter pylori (H. pylori) function from the activities of its key ingredients briefly described.

Aloe vera is a plant with antioxidant, anti-inflammatory, antitoxicity, analgesic, and antidiabetic properties and is used in traditional Chinese medicine for treatment of constipation and colitis. Aloe vera mitigates dextran sulfate sodium-induced rat ulcerative colitis by potentiating the colon mucus barrier [30]. A pilot randomized trial showed that Aloe vera was more effective (42\%) than placebo $(28 \%)$ in relieving IBS symptoms of 58 IBS patients at the trend level [18], and 8-week intervention with $30 \mathrm{ml}$ Aloe vera administered twice daily significantly decreased pain, discomfort, and flatulence in 33 individuals with constipationpredominated refractory IBS [31].

Acai is a phytochemical plant with antioxidant, antiinflammatory, and antigenotoxic effects [32-36]. Dried extract of acai berries improves ethanol-induced ulcer in rats [37]. Extract of acai seed attenuated experimental colitis in rats via the TLR-4/Cox-2/NF-k $\beta$ pathway [38]. Acai promotes jejunal tissue regeneration by enhancing the antioxidant response in 5-fluorouracil-induced mucositis [39]. Aqueous extract of acai increases blood flow acutely in rats [40]. Acai reduces the inflammatory response induced by antipsychotic drug olanzapine in macrophage cells [41]. Acai 
supplementation reduced hepatic oxidative stress of dams fed high-fat diet and increases antioxidant enzymes' gene expression in the offspring [42].

Inflammatory or ulcerating intestinal diseases can result in leakiness of the gut barrier [43], whereas citrus flavonoids can protect the intestinal barrier and protect against nonsteroidal anti-inflammatory drug-induced small intestine injury by promoting autophagy in vivo and in vitro [44-46]. Total citrus flavonoids attenuate nonalcoholic steatohepatitis via regulating the gut microbiota and bile acid metabolism in mice [47]. Citrus flavonoid eriocitrinon dosedependently attenuated chemically induced tonic visceral nociception and acute phasic thermal nociception in incisional nociceptive hyperalgesia mice via the opioid receptor and GABAA receptor-mediated mechanism [48]. Consumption of citrus flavonoids for 12 weeks reduced the lowdensity lipoprotein cholesterol (LDL) level and waist circumference in healthy subjects [49] and reduced oxidation of LDL in naive cardiovascular subjects [50].

Hypomagnesemia is common in patients with gastrointestinal losses and other diseases [51] that can alter gut microbiota and leads to depressive-like behavior [52]. Administration of magnesium sulfate effectively attenuated the pneumoperitoneum-related hemodynamic instability during gastrointestinal laparoscopy and improved postoperative pain at serum magnesium concentrations above $2 \mathrm{mmol} / \mathrm{L}$ [53]. Magnesium citrate plus sodium picosulfate administration is effective and safe for colon cleansing [54]. Magnesium sulfate attenuates hypoxia-induced lethality and oxidative damage in mice [55]. Altered intestinal motility, secretion, absorption, and gastrointestinal transit time (GITT) are characters of gastrointestinal complications, whereas magnesium can control gastrointestinal smooth muscle contraction through the $\alpha$-adrenoceptor antagonist pathway [56].

Vitamin C (ascorbic acid, ascorbate) deficiency is a character of patients with gastric disease, peptic ulcer, and ulcer hemorrhage due to decreased absorption, insufficient intake, increased metabolic requirement, and rapid destruction of vitamin $\mathrm{C}$ in the GI tract [57-59] that can be reversed by $H$. pylori eradication and worsened by proton pump inhibitor therapy. Dietary supplements of vitamin C protect gastric corpus from oxidative damage to the gastric mucosa by scavenging free radicals and attenuating the H. pylori-induced inflammatory cascade and decrease incidence of bleeding from peptic ulcer disease [60]. Vitamin C alleviates acute enterocolitis in Campylobacter jejuni-infected mice with the anti-inflammatory effects extended to extraintestinal compartments including the liver, kidneys, and lungs [61].

A meta-analysis of randomized controlled trials (RCTs) suggests that peppermint oil is safe and effective in improving global IBS symptoms and abdominal pain [15]. A network meta-analysis also ranked peppermint oil as the most effective supplement for IBS compared to soluble fiber, antispasmodic drugs, and gut-brain modulators [14]. However, other RCTs showed no significant effect of peppermint oil on IBS symptoms [20]. Similarly, while one study showed Aloe vera extract was effective treatment of IBS
[19], other RTCs showed no effect of Aloe vera on IBS $[16-18,62,63]$. The cause of the discrepant efficacies between different studies remains unknown but may be due to variations in quality, quantity, and absorption route of bioactive ingredients or due to variation in CGS subtype and severity, age, gender, comorbidity, and premedical treatment. Understanding the role of these potential influencing factors could help design better intervention strategies.

The aim of this randomized placebo-controlled doubleblind trial was to evaluate the safety and efficacy of ColonVita on the chronic gastrointestinal symptoms and the quality of life in old adults with chronic postprandial abdominal pain, indigestion, abdominal distension, anorexia, heartburn, vomiting, constipation, and chronic diarrhea, by using the gastrointestinal quality of life index (GIQLI) which is a specific measure for the evaluation of health status and treatment effectiveness for adults with chronic gastrointestinal condition [64]. GIQLI has been validated as a reliable scale to evaluate adults with chronic gastrointestinal problems among the Chinese-speaking population [65].

\section{Materials and Methods}

\subsection{Participants}

2.1.1. Inclusion Criteria, Recruitments, and Sample Size Estimation. The recruitment of the participants occurred between November 18, 2011, and December 25, 2011, and the follow-up observation was completed on March 31, 2012, at Jiaxing Lu Community Health Service Center, Lujiazui, Shanghai, China. Participants were recruited by self-referral in response to media coverage and word of mouth. All study procedures were conducted in accordance with the Helsinki Declaration of 1975, and written informed consent form was obtained from all participants prior to enrollment into the study.

Subjects who met the first and one of the other two following criteria were eligible for the study. Inclusion criteria: (1) 50 years or older male or female; (2) stomach symptoms such as abdominal pain after a meal, dyspepsia, bloating, anorexia, heartburn, and vomiting etc., and (3) intestinal symptoms such as constipation, chronic diarrhea, and so on.

The estimated sample size was based on the hypothesis that the expected means \pm standard deviation of the total GIQLI score in ColonVita groups would be $116.0 \pm 10.0$ after the intervention. The expected means \pm standard deviation of each group would be about $110.0 \pm 10.0$ after the intervention. The $\alpha$ level was set as 0.05 , and the power was set as 0.80 . The calculated sample size is 45 per group, and the total sample size was 90 . With an expected $10 \%$ dropout rate $(n=9)$, it is estimated that at least 100 patients would be required, with 50 participants per group.

2.2. Randomization and Blindness. Participants were randomly assigned to the intervention group (ColonVita) and the control group (placebo). The randomization was performed using a predetermined randomization code which was generated by a random number generator. 
Trial participants and community doctors were both blinded from the treatment (double-blind trial). Of the 100 enrolled participants, 50 subjects were assigned to the ColonVita group and 50 subjects to the placebo group. All participants completed the 12-week study.

The participants received similar-looking capsules in color-coded bottles (white bottles for ColonVita and yellow bottles for placebo control). Neither the subjects nor the medical doctors, including the study principal investigator, knew the specific color code until the completion of the study. Both the ColonVita tablets and the control tablets were manufactured and supplied by Garda Vita Inc. (Costa Mesa, California, USA). Each participant was instructed to take three tablets of ColonVita after supper during the first 10 days of the study and afterwards take one tablet per day for the rest of the study. A new batch of supplements was dispensed every month during follow-up sessions. Each ColonVita tablet contains the following active ingredients: $331 \mathrm{mg}$ blend of Aloe extract, acai tropical fruit extract, citrus bioflavonoids, peppermint leaves extract (200:1), $150 \mathrm{mg}$ of magnesium hydroxide, and $30 \mathrm{mg}$ of vitamin $\mathrm{C}$. The placebo is composed of wheat flour powder.

2.3. Evaluation of Medical History and Severity of GI Symptoms. A medical questionnaire that includes birth of date, sex, medical history, family history, smoking, drinking habits, and current medicine use was collected from each participant. A Chinese version of the gastrointestinal quality of life index (GIQLI) was used to estimate the severity of the gastrointestinal symptoms and the quality of life which is specially designed for people with digestive system symptoms $[64,65]$. The sensitivity of the GIQLI is estimated at 0.92 , and the reliability is greater than 0.90 .

This GIQLI scale is a 36-item survey with four aspects: (1) the core gastrointestinal digestion symptom (19 items, $\mathrm{q} 1-\mathrm{q} 9, \mathrm{q} 27-\mathrm{q} 36,0-76)$, (2) psychological/emotional wellbeing (5 items, q10-q14, 0-20), (3) physical well-being (7 items, q15-q21, 0-28), and (4) daily life and social activities (5 items, q22-q26, 0-20). Each survey question has five response options ( $0-4$, from worst to best condition). The total cumulative score of the GIQLI scale is at a range of 0-144 points. The better the function/quality of life, the higher the score; the average score of normal people is 125.8 points.

Baseline values and changes in the GIQLI scores of GIrelated symptoms were evaluated before and after the 12week intervention. All participants were followed up each month in order to check compliance and adverse effects.

2.4. Statistics Analysis. EpiData 3.02 software was used for the data entry, and SPSS 20 software was used for statistical analysis. Group data were presented as the mean \pm s.d. Differences between the ColonVita and placebo groups were compared using Student's $t$-test for quantitative variables with normal distribution and Mann-Whitney $U$ test for variables with nonnormal distribution or the chi-square test for categorized variables. The alpha level of $P>0.05$ was chosen as being statistically significant. All $P$ values reported were 2 -sided.

\section{Results}

3.1. Demographic Characteristics and Medical History of the Participants. There were no significant differences between the ColonVita and placebo groups in the proportions of gender $(18 \mathrm{M} / 32 \mathrm{~F}$ vs. $19 \mathrm{M} / 31 \mathrm{~F})\left(\chi^{2}=0.043, P=0.84\right)$, ages $(63.05 \pm 10.18$ vs. $63.14 \pm 8.59)(t=-0.047, P=0.962)$, people over 60 years of age $(46.0 \%$ vs. $52.0 \%) \quad\left(\chi^{2}=0.360\right.$, $P=0.548)$, alcohol drinking $(14.0 \%$ vs. $18.0 \%)\left(\chi^{2}=0.298\right.$, $P=0.585)$, cardiovascular disease $(46.0 \%$ vs. $42.0 \%)$ $\left(\chi^{2}=0.162, P=0.687\right)$, use of medication $(57.9 \%$ vs. $61.5 \%)$ $\left(\chi^{2}=0.11, P=0.74\right)$, and the history of medication use for gastrointestinal symptoms $(44.0 \%$ vs. $48.0 \%)\left(\chi^{2}=0.161\right.$, $P=0.688)$ (Table 1$)$.

\subsection{Baseline of Gastrointestinal Quality of Life Index (GIQLI).} There are no baseline differences between the ColonVita and placebo groups in the total GIQLI score (101.12 \pm 16.87 vs. $101.80 \pm 16.48, P>0.05)$ and in the subdomain scores of the

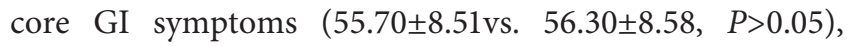
psychological/emotional state $(13.22 \pm 3.18$ vs. $13.28 \pm 2.84$, $P>0.05)$, physiological function $(17.82 \pm 5.42$ vs. $17.68 \pm 5.15$, $P>0.05)$, and daily life and social activities (14.38 \pm 3.12 vs. 14.54 $\pm 3.16, P>0.05$ ) (Table 2).

After the 12-week intervention, no significant differences $(P>0.05)$ were found between the ColonVita and placebo groups in the total GIQLI score $(114.78 \pm 9.62$ vs. $111.74 \pm 13.01, P>0.05)$, the core GI symptoms (63.22 \pm 5.19 vs. $61.66 \pm 7.33, P>0.05)$, psychological emotional state $(14.72 \pm 1.98$ vs. $14.26 \pm 2.11, P>0.05)$, physical function $(22.04 \pm 3.16$ vs. $21.42 \pm 3.71, P>0.05)$, and daily life and social activity $(14.80 \pm 2.62$ vs. $14.40 \pm 2.91, P>0.05)(\mathrm{Ta}-$ ble 3$)$. Although all scores of GIQLI subdomains were improved after the 12-week intervention, no difference was found between the ColonVita and placebo groups in beforeafter changes of score values $(P>0.05)$ (Table 3$)$.

Stratified analysis showed no influence of gender, alcohol drinking, and use of GI medicine on the total GIQLI score in response to the 12-week interaction. However, stratified analysis showed a differential response within the age and CVD subgroups.

While no treatment difference was found in people under 60 years, the total score of GIQLI and the score of core GI symptoms were significantly improved in the ColonVita group than in the placebo group of people $\geq 60$ years $(118.09 \pm 7.88$ vs. $109.50 \pm 16.71, P<0.05 ; 64.61 \pm 3.99$ vs. $60.00 \pm 8.65, P<0.05$, respectively) (Table 4 ).

Of CVD-free participants, supplement of ColonVita for 12 weeks resulted in significantly better improvement than placebo treatment in the total score of GIQLI $(116.74 \pm 9.38$ vs. $110.10 \pm 14.28)(P<0.05)$ and in core GI symptoms at a trend level $(63.11 \pm 4.53$ vs. $59.93 \pm 8.03)(P=0.072)$, in an increased value of the total GIQLI score $(17.22 \pm 13.97$ vs. $9.14 \pm 15.06)(P<0.05)$ and in an increased value of the core GI symptom score $(10.89 \pm 8.26$ vs. $5.76 \pm 8.23)(P<0.05)$ 
TABLE 1: Characteristics of the study participants ${ }^{\mathrm{a}}(N=100)$.

\begin{tabular}{lccr}
\hline & ColonVita $(n=50)$ & Placebo $(n=50)$ & $\chi^{2}$ \\
\hline Sex: male $(N)$ & $N(\%)$ & $N(\%)$ & 0.043 \\
Age (mean \pm s.d.) & $18(36.0)$ & $19(18.0)$ & -0.047 \\
Age $\geq 60$ year & $63.05 \pm 10.18$ & $63.14 \pm 8.59$ & 0.360 \\
Alcohol drink & $23(46.0)$ & $26(52.0)$ & 0.936 \\
History of CVD & $7(14.0)$ & $9(18.0)$ & 0.298 \\
Medication & $23(46.0)$ & $21(42.0)$ & 0.162 \\
\hline
\end{tabular}

${ }^{\mathrm{a}}$ Data are numbers of individuals (\%) unless otherwise indicated. CVD, cardiovascular disease.

TABLe 2: Baseline GIQLI scores in ColonVita and placebo groups

\begin{tabular}{lccr}
\hline & \multicolumn{2}{c}{ GIQLI (mean \pm standard deviation) } & $t$ \\
& ColonVita group $(n=50)$ & Placebo group $(n=50)$ & 0.839 \\
\hline Total score & $101.12 \pm 16.87$ & $101.80 \pm 16.48$ & -0.204 \\
Core symptom & $55.70 \pm 8.51$ & $56.30 \pm 8.58$ & -0.351 \\
Psychological item & $13.22 \pm 3.18$ & $13.28 \pm 2.84$ & -0.100 \\
Physical item & $17.82 \pm 5.42$ & $17.68 \pm 5.15$ & 0.132 \\
Social item & $14.38 \pm 3.12$ & $14.54 \pm 3.16$ & 0.921 \\
\hline
\end{tabular}

$t, t$-test.

TABLE 3: Group differences in the GIQLI score and change in the value after 12-week intervention.

\begin{tabular}{|c|c|c|c|c|}
\hline & GIQI & & $t$ & $D$ \\
\hline & ColonVita $(n=50)$ & Placebo $(n=50)$ & $t$ & $P$ \\
\hline Total score & $114.78 \pm 9.62$ & $111.74 \pm 13.01$ & 1.329 & 0.187 \\
\hline Core symptom & $63.22 \pm 5.19$ & $61.66 \pm 7.33$ & 1.229 & 0.222 \\
\hline Psychological item & $14.72 \pm 1.98$ & $14.26 \pm 2.11$ & 1.125 & 0.263 \\
\hline Physical item & $22.04 \pm 3.16$ & $21.42 \pm 3.71$ & 0.900 & 0.370 \\
\hline Social item & $14.80 \pm 2.62$ & $14.40 \pm 2.91$ & 0.722 & 0.472 \\
\hline Differences in total score & $13.66 \pm 18.52$ & $9.94 \pm 16.43$ & 1.063 & 0.291 \\
\hline Differences in core symptom & $7.52 \pm 8.84$ & $5.36 \pm 7.48$ & 1.319 & 0.190 \\
\hline Differences in psychological item & $1.50 \pm 3.46$ & $0.98 \pm 3.09$ & 1.793 & 0.430 \\
\hline Differences in physical item & $4.22 \pm 6.13$ & $3.74 \pm 6.28$ & 0.397 & 0.700 \\
\hline Differences in social item & $0.42 \pm 3.68$ & $-0.14 \pm 3.17$ & 0.815 & 0.417 \\
\hline
\end{tabular}

$t$, $t$-test.

that were similar between ColonVita and placebo groups with a CVD history $(114.43 \pm 11.62$ vs. $114.33 \pm 13.22)$ $(P>0.05)(12.30 \pm 26.13$ vs. $12.43 \pm 22.76 \mathrm{f}),(P>0.05)$ and $(5.48 \pm 9.99$ vs. $6.43 \pm 8.59$ for core GI symptoms $)(P>0.05)$

(Table 5), respectively.

Within GI medication-free participants, ColonVita supplement resulted in better improvement in the psychological/emotional well-being score at a trend level $(1.73 \pm 2.64$ vs. $0.00 \pm 2.60)(P=0.098)$, whereas a significant increase in the score value of the daily activity and social function than placebo was found after ColonVita supplement in participants with prior GI medicine treatment $(1.73 \pm 2.64$ vs. $0.00 \pm 2.60)(P<0.05)$ (Table 6$)$.

\subsection{Colon Vita and Placebo Differentially Improved Individual} Core GI Symptoms. ColonVita treatment significantly $(P>0.05)$ improved the scores of 16 individual items of the core GI symptoms ( $\mathrm{q} 1-\mathrm{q} 6, \mathrm{q} 8, \mathrm{q} 9, \mathrm{q} 27-\mathrm{q} 33$, and $\mathrm{q} 35$ ) compared to the scores of 10 individual items significantly improved by the placebo $(P>0.05)$ (q1-q5, q9, q27, q32-q33, and q35) (Table 7). The 6 items specifically improved by ColonVita are as follows: (1) time troubled by gurgling noises from the abdomen (q6), (2) time of having good appetite (q8), (3) time of not feeling well and eating slowly (q28), (4) time of feeling difficulty in swallowing (q29), (5) time of feeling urgent defecating (q30), and (6) frequency of diarrhea (q31).

3.4. Three Specific Core GI Symptoms Were Better Improved by ColonVita Supplement. ColonVita supplement resulted in better improvement in three of the 19 core GI symptoms scores than placebo in the two samples rank-sum test: (1) bowel sound trouble (q6) (56.55 vs. 44.45) $(P<0.05)$, (2) feeling unwell for eating slowly (q28) (56.57 vs. 44.47) $(P<0.05)$, and $(3)$ feeling defecating urgent (q30) (56.20 vs. 44.80$)(P<0.05)$ (Table 8$)$.

3.5. Five Core GI Symptoms Show Better Remission Rate after ColonVita Intervention. The remission rate (defined as the percentage of participants showing positive improvement after the intervention) of the core GI symptoms was generally greater in the ColonVita group than in the placebo 
TABLe 4: Effect of age on the GIQLI score after 12-week ColonVita intervention.

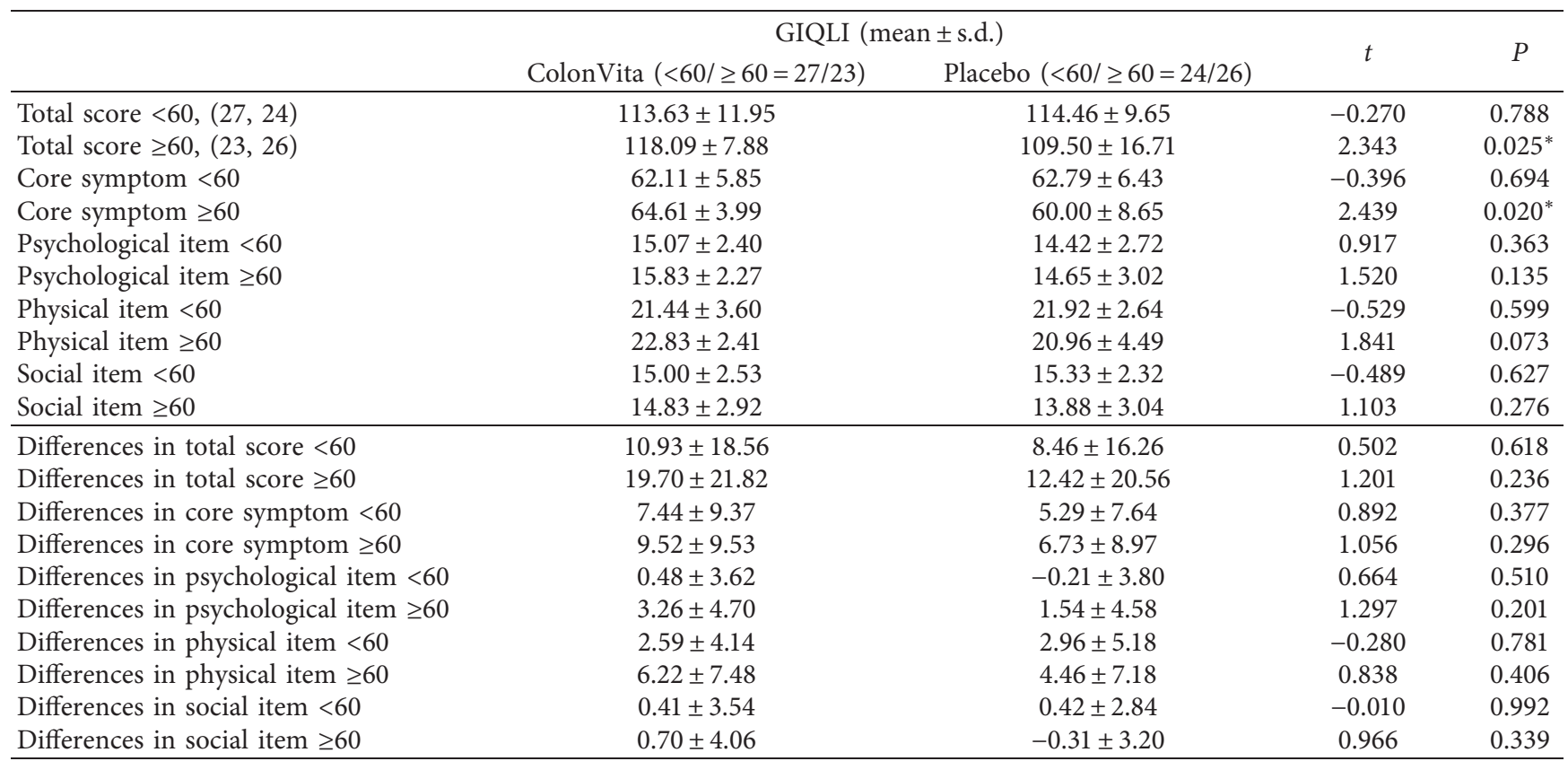

$t$, $t$-test. ${ }^{*}, P<0.05$.

TABle 5: Effect of CVD on the GIQLI score after 12-week ColonVita intervention.

\begin{tabular}{|c|c|c|c|c|}
\hline & \multicolumn{2}{|c|}{ GIQLI (mean \pm s.d.) } & \multirow{2}{*}{$t$} & \multirow{2}{*}{$P$} \\
\hline & ColonVita $(\mathrm{CVD} /$ non $=23 / 27)$ & Placebo $(\mathrm{CVD} / \mathrm{non}=21 / 29)$ & & \\
\hline Total score, CVD & $114.43 \pm 11.62$ & $114.33 \pm 13.22$ & 0.027 & 0.979 \\
\hline Total score, no CVD & $116.74 \pm 9.38$ & $110.10 \pm 14.28$ & 2.069 & $0.044^{*}$ \\
\hline Core symptom, CVD & $63.43 \pm 5.97$ & $63.29 \pm 6.99$ & 0.076 & 0.940 \\
\hline Core symptom, no CVD & $63.11 \pm 4.53$ & $59.93 \pm 8.03$ & 1.841 & 0.072 \\
\hline Psychological, CVD & $14.83 \pm 2.57$ & $14.14 \pm 2.92$ & 0.825 & 0.414 \\
\hline Psychological, no CVD & $15.93 \pm 2.06$ & $14.83 \pm 2.82$ & 1.656 & 0.103 \\
\hline Physical item, CVD & $21.91 \pm 2.75$ & $22.33 \pm 4.08$ & $-0.397^{*}$ & 0.694 \\
\hline Physical item, no CVD & $22.22 \pm 3.51$ & $20.76 \pm 3.33$ & 1.600 & 0.115 \\
\hline Social item, CVD & $14.26 \pm 3.12$ & $14.57 \pm 2.82$ & -0.345 & 0.732 \\
\hline Social item, no CVD & $15.48 \pm 2.16$ & $14.59 \pm 2.81$ & 1.331 & 0.189 \\
\hline Differences in total score, CVD & $12.30 \pm 26.13$ & $12.43 \pm 22.76$ & -0.017 & 0.987 \\
\hline Differences in total score, no CVD & $17.22 \pm 13.97$ & $9.14 \pm 15.06$ & 2.079 & $0.042^{*}$ \\
\hline Differences in core symptom, CVD & $5.48 \pm 9.99$ & $6.43 \pm 8.59$ & -0.337 & 0.738 \\
\hline Differences in core symptom, no CVD & $10.89 \pm 8.26$ & $5.76 \pm 8.23$ & 2.326 & $0.024^{*}$ \\
\hline Differences in psychological item, CVD & $2.00 \pm 5.46$ & $1.10 \pm 5.92$ & 0.527 & 0.601 \\
\hline Differences in psychological item, no CVD & $1.56 \pm 3.19$ & $0.41 \pm 2.59$ & 1.476 & 0.146 \\
\hline Differences in physical item, CVD & $5.00 \pm 7.97$ & $5.76 \pm 8.01$ & -0.316 & 0.754 \\
\hline Differences in physical item, no CVD & $3.63 \pm 4.02$ & $2.28 \pm 4.23$ & 1.225 & 0.226 \\
\hline Differences in social item, CVD & $-0.17 \pm 4.70$ & $-0.86 \pm 3.38$ & 0.549 & 0.586 \\
\hline Differences in social item, no CVD & $1.15 \pm 2.66$ & $0.69 \pm 2.61$ & 0.652 & 0.517 \\
\hline
\end{tabular}

$t$, $t$-test. ${ }^{*}, P<0.05$.

group, and 5 of them reached significant levels, i.e., epigastria satiety $\left(72 \%\right.$ vs. $\left.48 \%, \chi^{2}=6.0, P=0.014\right)(\mathrm{Q} 2)$, excessive hiccups (58\% vs. $\left.32 \%, \chi^{2}=6.83, P=0.009\right)(\mathrm{Q} 5)$, audible bowel sounds ( $50 \%$ vs. $28 \%, \chi^{2}=5.086, P=0.024$ ) (Q6), discomfort due to slow eating ( $38 \%$ vs. $18 \%, \chi^{2}=4.96$, $P=0.026)$ (Q28), and urge to defecate (46\% vs. $18 \%$, $\left.\chi^{2}=9.0, P=0.003\right)(\mathrm{Q} 30)$ were significantly better in the ColonVita group than in the placebo group after the intervention (Table 9).

\section{Discussion}

In this double-blind placebo-controlled randomized trial, all participants completed the 12-week study and reported no side effects of ColonVita. No significant difference was found in the total score of GIQLI between ColonVita and placebo groups after the 12-week intervention, although ColonVita improved the total score of GIQLI to a greater extent than placebo (15\% vs.10\%). Furthermore, ColonVita supplement 
TABLe 6: Effect of GI medication on the GIQLI score after ColonVita intervention.

\begin{tabular}{|c|c|c|c|c|}
\hline & \multicolumn{2}{|c|}{ GIQLI (mean \pm s.d.) } & \multirow{2}{*}{$t$} & \multirow{2}{*}{$P$} \\
\hline & ColonVita $(\mathrm{med} /$ non = 22/28) & Placebo $(\mathrm{med} / \mathrm{non}=24 / 26)$ & & \\
\hline Total score, med & $119.00 \pm 8.93$ & $114.50 \pm 13.11$ & 1.349 & 0.184 \\
\hline Total score, nonmed & $113.07 \pm 10.92$ & $109.46 \pm 14.36$ & 1.044 & 0.301 \\
\hline Core symptom, med & $64.77 \pm 4.70$ & $62.33 \pm 8.11$ & $1.260^{*}$ & 0.215 \\
\hline Core symptom, nonmed & $62.07 \pm 5.32$ & $60.42 \pm 7.38$ & 0.946 & 0.348 \\
\hline Psychological, med & $16.23 \pm 2.05$ & $15.54 \pm 2.72$ & 0.960 & 0.343 \\
\hline Psychological, nonmed & $14.79 \pm 2.41$ & $13.62 \pm 2.70$ & 1.683 & 0.098 \\
\hline Physical item, med & $22.77 \pm 3.59$ & $22.25 \pm 2.97$ & 0.541 & 0.592 \\
\hline Physical item, nonmed & $21.54 \pm 2.72$ & $20.65 \pm 4.20$ & 0.910 & 0.368 \\
\hline Social item, med & $15.23 \pm 2.27$ & $14.38 \pm 2.18$ & 1.299 & 0.201 \\
\hline Social item, nonmed & $14.68 \pm 2.99$ & $14.77 \pm 3.28$ & -0.106 & 0.916 \\
\hline Differences in total score, med & $23.95 \pm 18.41$ & $15.63 \pm 17.69$ & 1.564 & 0.125 \\
\hline Differences in total score, nonmed & $7.89 \pm 19.33$ & $5.81 \pm 18.38$ & 0.406 & 0.687 \\
\hline Differences in core symptom, med & $12.05 \pm 8.90$ & $8.29 \pm 8.92$ & 1.428 & 0.160 \\
\hline Differences in core symptom, nonmed & $5.54 \pm 8.92$ & $3.96 \pm 7.26$ & 0.708 & 0.482 \\
\hline Differences in psychological item, med & $3.59 \pm 4.30$ & $2.08 \pm 4.10$ & 1.218 & 0.230 \\
\hline Differences in psychological item, nonmed & $0.32 \pm 3.87$ & $-0.58 \pm 4.10$ & 0.828 & 0.411 \\
\hline Differences in physical item, med & $6.59 \pm 6.80$ & $5.25 \pm 6.23$ & 0.698 & 0.489 \\
\hline Differences in physical item, nonmed & $2.43 \pm 4.93$ & $2.35 \pm 6.12$ & 0.055 & 0.957 \\
\hline Differences in social item, med & $1.73 \pm 2.64$ & $0.00 \pm 2.60$ & 2.232 & $0.031^{*}$ \\
\hline Differences in social item, nonmed & $-0.39 \pm 4.25$ & $0.08 \pm 3.42$ & -0.445 & 0.658 \\
\hline
\end{tabular}

$t$, t-test. ${ }^{*}, P<0.05$.

TABLe 7: Differential impact of ColonVita and placebo on the scores of core GI symptoms (Wilcoxon signed-rank test).

\begin{tabular}{|c|c|c|c|c|c|}
\hline & \multirow{2}{*}{ Item } & \multicolumn{2}{|c|}{ ColonVita group } & \multicolumn{2}{|c|}{ Placebo group } \\
\hline & & $z$ & $P$ & $z$ & $P$ \\
\hline Q1 & How often do you feel abdominal pain? & 2.926 & $0.003^{* *}$ & 3.869 & $0.001^{* *}$ \\
\hline Q2 & How often feels epigastria satiety? & 4.526 & $0.001^{* *}$ & 3.734 & $0.001^{* *}$ \\
\hline Q3 & How often feels abdominal distension? & 3.523 & $0.001^{* *}$ & 3.611 & $0.001^{* *}$ \\
\hline Q4 & How often with anal excessive exhaust? & 4.162 & $0.001^{* *}$ & 3.289 & $0.001^{* *}$ \\
\hline Q5 & How often with excessive hiccups? & 3.778 & $0.001^{* *}$ & 3.035 & $0.002^{* *}$ \\
\hline Q6 & How often troubled by bowel sound? & 3.390 & $0.001^{* *}$ & 1.487 & 0.137 \\
\hline Q7 & How often frequent bowel movements? & 1.043 & 0.297 & 0.504 & 0.614 \\
\hline Q8 & How often feels good appetite? & 2.177 & $0.029^{*}$ & 1.673 & 0.094 \\
\hline Q9 & How often ill restricted your diet type? & 2.183 & $0.029^{*}$ & 2.044 & $0.041^{*}$ \\
\hline Q27 & How often feels sour regurgitation? & 4.440 & $0.001^{* *}$ & 2.625 & $0.009^{* *}$ \\
\hline Q28 & How often feels unwell for eating slowly? & 2.997 & $0.003^{* *}$ & 0.043 & 0.965 \\
\hline Q29 & How often have difficulty swallowing? & 2.840 & $0.005^{* *}$ & 1.633 & 0.102 \\
\hline Q30 & How often feels defecating urgent? & 3.470 & $0.001^{* *}$ & 1.734 & 0.083 \\
\hline Q31 & How often with diarrhea? & 2.202 & $0.028^{*}$ & 1.127 & 0.260 \\
\hline Q32 & How often with constipation? & 2.830 & $0.005^{* *}$ & 3.260 & $0.001^{* *}$ \\
\hline Q33 & How often feels nausea? & 3.621 & $0.001^{* *}$ & 3.251 & $0.001^{* *}$ \\
\hline Q34 & How often blood in stool? & 1.000 & 0.317 & 1.000 & 0.317 \\
\hline Q35 & How often feels heartburn? & 3.552 & $0.001^{* *}$ & 4.134 & $0.001^{* *}$ \\
\hline Q36 & How often with fecal incontinence? & 1.000 & 0.317 & 1.000 & 0.317 \\
\hline
\end{tabular}

improved more individual items of the core GIQLI symptoms and to a greater extent than placebo. Specifically, ColonVita supplement significantly $(P>0.05)$ improved the scores of 16 items of the 19 core GI symptoms compared to 10 items improved by placebo and improvement in 3 core GI symptoms scores, i.e., bowel sound trouble, feeling unwell for eating slowly, and feeling defecating urgency were significantly greater after ColonVita than after placebo intervention. ColonVita supplement also resulted in a significantly greater remission rate than placebo in 5 core GI symptoms, i.e., epigastria satiety, bowel sound trouble, excessive hiccups, feeling unwell for eating slowly, and feeling urgent to defecate were significantly greater. These results support beneficial effects of ColonVita supplement on core GI symptoms in old adults with CGS.

The significant placebo effect on the subjective GIQLI endpoints is in agreement with the recent review and metaanalysis of clinical trials that placebo intervention is associated with improvements in subjective clinical outcomes (response and remission) of gastrointestinal diseases, 
TABLE 8: A comparison of the ColonVita and placebo groups' core GI symptoms scores before and after the intervention (two samples' ranksum test).

\begin{tabular}{|c|c|c|c|c|c|}
\hline & Item & $\begin{array}{l}\text { ColonVita group } \\
\text { Mean rank }\end{array}$ & $\begin{array}{l}\text { Placebo group } \\
\text { Mean rank }\end{array}$ & $z$ & $P$ \\
\hline Q1 & How often do you feel abdominal pain? & 49.20 & 51.80 & -0.500 & 0.617 \\
\hline Q2 & How often feels epigastria satiety? & 54.07 & 46.93 & -1.311 & 0.190 \\
\hline Q3 & How often feels abdominal distension? & 52.44 & 48.56 & -0.705 & 0.481 \\
\hline Q4 & How often with anal excessive exhaust? & 53.94 & 47.06 & -1.276 & 0.202 \\
\hline Q5 & How often with excessive hiccups? & 54.93 & 46.07 & -1.625 & 0.104 \\
\hline Q6 & How often troubled by bowel sound? & 56.55 & 44.45 & -2.234 & $0.025 *$ \\
\hline Q7 & How often frequent bowel movements? & 52.42 & 48.58 & -0.706 & 0.480 \\
\hline Q8 & How often feels good appetite? & 52.35 & 48.65 & -0.660 & 0.509 \\
\hline Q9 & How often ill restricted your diet type? & 51.20 & 49.80 & -0.252 & 0.801 \\
\hline Q27 & How often feels sour regurgitation? & 54.81 & 46.19 & -1.555 & 0.120 \\
\hline Q28 & How often feels unwell for eating slowly? & 56.57 & 44.43 & -2.337 & $0.019^{*}$ \\
\hline Q29 & How often have difficulty swallowing? & 53.49 & 47.51 & -1.544 & 0.122 \\
\hline Q30 & How often feels defecating urgent? & 56.20 & 44.80 & -2.227 & $0.026^{*}$ \\
\hline Q31 & How often with diarrhea? & 53.09 & 47.91 & -1.073 & 0.283 \\
\hline Q32 & How often with constipation? & 52.19 & 48.81 & -0.655 & 0.513 \\
\hline Q33 & How often feels nausea? & 52.95 & 48.05 & -0.939 & 0.348 \\
\hline Q34 & How often blood in stool? & 49.03 & 51.97 & -1.342 & 0.180 \\
\hline Q35 & How often feels heartburn? & 47.61 & 53.39 & -1.072 & 0.284 \\
\hline Q36 & How often with fecal incontinence? & 50.02 & 50.98 & -0.438 & 0.661 \\
\hline
\end{tabular}

*, $P<0.05$.

TABLE 9: Remission rate of the core GI symptoms after the intervention.

\begin{tabular}{|c|c|c|c|c|c|}
\hline & Item & $\begin{array}{c}\text { ColonVita } \\
\%\end{array}$ & $\begin{array}{c}\text { Placebo } \\
\%\end{array}$ & $\chi^{2}$ & $P$ \\
\hline Q1 & How often do you feel abdominal pain? & 40.0 & 42.0 & 0.041 & 0.839 \\
\hline Q2 & How often feels epigastria satiety? & 72.0 & 48.0 & 6.000 & $0.014^{*}$ \\
\hline Q3 & How often feels abdominal distension? & 60.0 & 42.0 & 3.241 & 0.072 \\
\hline Q4 & How often with anal excessive exhaust? & 52.0 & 40.0 & 1.449 & 0.229 \\
\hline Q5 & How often with excessive hiccups? & 58.0 & 32.0 & 6.828 & $0.009^{* *}$ \\
\hline Q6 & How often troubled by bowel sound? & 50.0 & 28.0 & 5.086 & $0.024^{*}$ \\
\hline Q7 & How often frequent bowel movements? & 34.0 & 30.0 & 0.184 & 0.668 \\
\hline Q8 & How often feels good appetite? & 50.0 & 42.0 & 0.644 & 0.422 \\
\hline Q9 & How often ill restricted your diet type? & 42.0 & 40.0 & 0.041 & 0.839 \\
\hline Q27 & How often feels sour regurgitation? & 60.0 & 42.0 & 3.241 & 0.072 \\
\hline Q28 & How often feels unwell for eating slowly? & 38.0 & 18.0 & 4.960 & $0.026^{*}$ \\
\hline Q29 & How often have difficulty swallowing? & 22.0 & 10.0 & 2.679 & 0.102 \\
\hline Q30 & How often feels defecating urgent? & 46.0 & 18.0 & 9.007 & $0.003^{* *}$ \\
\hline Q31 & How often with diarrhea? & 30.0 & 18.0 & 1.974 & 0.160 \\
\hline Q32 & How often with constipation? & 40.0 & 28.0 & 1.604 & 0.205 \\
\hline Q33 & How often feels nausea? & 44.0 & 34.0 & 1.051 & 0.305 \\
\hline Q34 & How often blood in stool? & 2.0 & 2.0 & 0.001 & 1.000 \\
\hline Q35 & How often feels heartburn? & 40.0 & 54.0 & 1.967 & 0.161 \\
\hline Q36 & How often with fecal incontinence? & 2.0 & 6.0 & 1.042 & 0.307 \\
\hline
\end{tabular}

*, $P<0.05 .{ }^{* *}, P<0.01$.

probably through the gut-brain interaction and a mechanism of enhanced healing expectation and conditioning [66-69].

In this study, the efficacy of ColonVita on the outcome of IGQLI is influenced by age. While no differences were found between ColonVita supplement and placebo in people under 60 years, the total score of GIQLI and the core GI symptoms score were significantly improved by ColonVita supplement in participants $\geq 60$ years, indicating greater relieving effects of ColonVita in the older people.
As aging alone does not greatly impact the gastrointestinal tract or cause digestive dysfunction (including esophageal reflux, achalasia, dysphagia, dyspepsia, delayed gastric emptying, constipation, fecal incontinence, and fecal impaction) in old adults [70], the differential improvement between the age subgroups by ColonVita may be due to improvement in aging-related declines in the gut function and/or preservation/proliferation of nerve cells of the myenteric plexus that affects the surface area of the small intestine, digestive absorption, and mucosal defense to 
generate protective immunity and incidence of inflammation and oxidative stress [71, 72]. There are reports that putatively protective lactic acid bacteria, in general, and Bifidobacteria, in particular, were reduced in the elderly fecal flora, and the species diversity of the dominant fecal microflora increased with aging [5, 73-75].

It is also possible that ColonVita supplement may have reduced age-related adverse effects of a greater dosage of GI medication in the older group. It is known that the medication use and the associated adverse drug reactions increases with age, and gastrointestinal adverse effects of drug use are one of the most reported in the elderly [76]. Future study could evaluate if ColonVita supplement may improve age-related changes in the structure and function of the GI by either improving the intestinal flora or reducing the adverse drug reactions of the elderly.

In this study, cardiovascular disease (CVD) appeared to have influenced the outcome of ColonVita on GIQLI as ColonVita supplement significantly improved the total score of GIQLI and scores of core GI symptoms only in CVD-free group but not in those with CVD. While the mechanism is unknown, recent studies suggest that venous thromboembolism (VTE) is a common risk factor underlying both CGS and cardiovascular disease and is strongly related to older age and obesity [21, 22]. Cardiovascular disease and gastrointestinal disorders are top two major aging-associated health conditions that have greater decrements impact on functioning and well-being [77]. Because the contract and relaxation of the muscles lining the intestines to move food along the digestive tract can be weakened by venous thromboembolism (VTE) and by ischemic colitis that result in intermittent abdominal pain/discomfort, altered bowel patterns, and abdominal bloating/distension [6] and because the key active ingredients of ColonVita such as acai extract can improve blood flow in rats [40], reduce inflammatory response in macrophage cells [41], and reduce hepatic oxidative stress of dams fed high-fat diet and increases antioxidant enzymes' gene expression in the offspring [42], future studies should determine if the selective effectiveness of ColonVita on GIQLI in CVD-free subpopulation is unique to ColonVita or it is a general mechanism of dietary supplement rich in anti-inflammatory and antihemostasis potentials.

A potential link between CVD and gastrointestinal disorders [78-81] is in line with the lack of effectiveness of ColonVita on CGS in people with CGS-CVD comorbidity than in people without CGS-CVD comorbidity. It is known that myocardial ischemia and infarction can induce intestinal angina-related diarrhea, nausea, and vomiting [82,83]. Sharp and sporadic pains in the upper left side stomach and in the esophageal sphincter usually begins within an hour of eating a meal and lasts up to two hours due to the abnormal cardioelectrical activity. Acute intestinal ischemia-related pain may occur due to blood clots in intestinal arteries that usually originated in the heart by atrial fibrillation [84-87]. Although nausea is related to stomach pain, it may indicate heart diseases.

Recent genome-wide association studies (GWAS) show that missense mutations in the voltage-gated sodium channel gene SCN5A is a potential pathogenetic mechanism of CGS [88-94]. The SCN5A-encoded voltage-gated mechanosensitive $\mathrm{Na}^{+}$channel $\mathrm{Na}_{\mathrm{V}} 1.5$ is expressed in human gastrointestinal smooth muscle cells and interstitial cells of Cajal. $\mathrm{Na}_{\mathrm{V}} 1.5$ contributes to smooth muscle electrical slow waves and mechanical sensitivity. In predominantly Caucasian irritable bowel syndrome (IBS) patient cohorts, $2-3 \%$ of patients have SCN5A missense mutations that alter the $\mathrm{Na}_{\mathrm{V}} 1.5$ function and may contribute to IBS pathophysiology [93]. Moreover, a greater percentage of individuals with SCN5A mutations had constipation-predominant CGS (CGS-C, 31\%) than diarrhea-predominant CGS (CGS-D) $(10 \%, P<0.05)$ [95]. Other studies showed that patients with irritable bowel syndrome and SCN5A mutation exhibited decreased NaV1.5 current and mechanosensitivity [96-99].

A potential heterogenous pathogenesis of the CGS could underlie the lower efficacy of ColonVita in people with CVD. Although inflammatory bowel disease (IBD) and irritable bowel syndrome (IBS) share similar CGS symptoms, they may have different pathogenesis. The GI tissues of IBS are not permanently damaged by inflammation as they are in IBD and should have a better chance of recovery after effective intervention. One extrapolation from our results is that CVD is more closely associated with IBD than with IBS. Or the discrepant efficacy of ColonVita between the noCVD and CVD groups is due to potential more IBS patients in the no-CVD group than in the CVD group that may have more IBD patients.

This study has limitations. Due to limited resources, the subtypes of CGS, i.e., IBS and IBD were not diagnosed using endoscopy/colonoscopy, contrast radiography, magnetic resonance imaging (MRI), or computed tomography (CT). The number of participants is small for detecting overall effects of ColonVita on the GIQLI outcome. Blood and stool samples were not collected for genotyping or intestinal microflora analysis. Nevertheless, the discovery of aging, CVD-comorbidity, and CGS subtype as potential influencing factors would help design better trials in assessing herbal supplement in the management of CGS.

\section{Conclusions}

Despite that polyherb-based supplement, ColonVita did not show a significant effect on the total score of GIQLI; ColonVita supplement, however, improved 16 scores of the 19 core GI symptoms compared to 10 items improved by placebo in adults with CGS. In addition, the beneficial effects of ColonVita on GIQLI is more prominent in the elderly over $60 \mathrm{y}$ of age and in volunteers without the history of CVDs. These beneficial effects of ColonVita in certain subpopulation indicate that the effectiveness of peppermintbased ColonVita on GIQLI is influenced by age, genetic background, comorbidity, CGS subtype, and medication that should be determined in further studies, so that different and more effective treatments can be developed for each of the specific subtype of CGS. 


$\begin{array}{ll}\text { Abbreviations } \\ \text { APC: } & \text { Annual percentage change } \\ \text { CD: } & \text { Crohn's disease } \\ \text { CDC: } & \text { US Center for Disease Control } \\ \text { CGS: } & \text { Chronic gastrointestinal symptoms } \\ \text { CGS-C: } & \text { Constipation-predominant CGS } \\ \text { CGS-D: } & \text { Diarrhea-predominant CGS } \\ \text { ColonVita: } & \text { A polyherbal supplement } \\ \text { Cox-2: } & \text { Cyclooxygenase-2 } \\ \text { CT: } & \text { Computed tomography } \\ \text { CVD: } & \text { Cardiovascular disease } \\ \text { DASH: } & \text { Dietary Approaches to Stop Hypertension } \\ \text { GABAA: } & \text { } \text {-Aminobutyric acid type A receptors } \\ \text { GITT: } & \text { Gastrointestinal transit time } \\ \text { GIQLI: } & \text { Gastrointestinal quality of life index } \\ \text { GWAS: } & \text { Genome-wide association study } \\ \text { H. pylori: } & \text { Helicobacter pylori (c) } \\ \text { IBD: } & \text { Inflammatory bowel disease } \\ \text { IBS: } & \text { Irritable bowel syndrome } \\ \text { LDL: } & \text { Low-density lipoprotein } \\ \text { NF-kB: } & \text { Nuclear factor kappa-light-chain-enhancer of } \\ & \text { activated B cells } \\ \text { NIH: } & \text { National Institutes of Health } \\ \text { MRI: } & \text { Magnetic resonance imaging } \\ \text { NaV1.5: } & \text { Voltage-gated sodium channel V (Nav) } \\ \text { RCTs: } & \text { Randomized controlled trials } \\ \text { SCN5A: } & \text { Gene coding for voltage-gated sodium channel } \\ & \text { subtype 5A (NaV1.5) } \\ \text { TLR-4: } & \text { Toll-like receptor } 4 \\ \text { UC: } & \text { Ulcerative colitis } \\ \text { VTE: } & \text { Venous thromboembolism. } \\ & \end{array}$

\section{Data Availability}

The data used to support the findings of this study are available from the first author and the corresponding author upon request.

\section{Ethical Approval}

This study was approved by the Shanghai Jiao Tong University School of Public Health Institutional Review Board. All study procedures were conducted in accordance with the Helsinki Declaration of 1974.

\section{Consent}

Written informed consent form was obtained from all participants prior to enrollment into the study.

\section{Disclosure}

The sponsor had no role in the design or analysis of this study or the interpretation of the findings.

\section{Conflicts of Interest}

Tuong Nguyen is an employee of DRM Resources. All other authors have declared that they have no competing or potential conflicts of interest in the study.

\section{Authors' Contributions}

JR, RS, and TN conceived experiment; TS, GX, and YC designed the experiments; GX, YC, JZ, and ZC recruited the participants; GX, JZ, BZ, and GX analyzed the data; GX wrote the paper. All authors read and approved the final manuscript and had full access to the study data.

\section{Acknowledgments}

This study was funded, in part, by DRM Resources (Costa Mesa, California, USA).

\section{References}

[1] E. J. Ross, H. Vivier, J. E. Cassisi, and R. D. Dvorak, "Gastrointestinal health: an investigation of mediating effects on mood and quality of life," Health Psychology Open, vol. 7, no. 2, Article ID 2055102920974524, 2020.

[2] Y. Qiu, W. Ren, Y. Liu, W.-E. Chen, X.-H. Pan, and J.-J. Ren, "Disease burden of inflammatory bowel disease in China from 1990 to 2017: findings from the global burden of diseases 2017," EClinicalMedicine, vol. 27, Article ID 100544, 2020.

[3] C. V. Almario, M. L. Ballal, W. D. Chey, C. Nordstrom, D. Khanna, and B. M. R. Spiegel, "Burden of gastrointestinal symptoms in the United States: results of a nationally representative survey of over 71,000 Americans," American Journal of Gastroenterology, vol. 113, no. 11, pp. 1701-1710, 2018.

[4] J. F. Pierre, R. Hinterleitner, R. Bouziat et al., "Dietary antioxidant micronutrients alter mucosal inflammatory risk in a murine model of genetic and microbial susceptibility," The Journal of Nutritional Biochemistry, vol. 54, pp. 95-104, 2018.

[5] K. Saunier and J. Doré, "Gastrointestinal tract and the elderly: functional foods, gut microflora and healthy ageing," Digestive and Liver Disease, vol. 34, no. Suppl 2, pp. S19-S24, 2002.

[6] S. hervé, L. Beaugerie, Y. Bouhnik et al., "Irritable bowel syndrome is more frequent in patients hospitalized for ischaemic colitis: results of a case-control study," NeuroGastroenterology and Motility, vol. 21, no. 11, pp. 1170-e102, 2009.

[7] S. L. Prescott, "Early nutrition as a major determinant of "immune health": implications for allergy, obesity and other noncommunicable diseases," Nestle Nutrition Institute workshop series, vol. 85, pp. 1-17, 2016.

[8] G. Hogue and R. Adams, "Lower gastrointestinal conditions: malabsorption syndromes," FP essentials, vol. 483, pp. 20-24, 2019.

[9] G.-E. Séralini, E. Clair, R. Mesnage et al., "Republished study: long-term toxicity of a roundup herbicide and a rounduptolerantgenetically modified maize," Environmental Sciences Europe, vol. 26, no. 1, p. 14, 2014.

[10] E. Dimidi and K. Whelan, "Food supplements and diet as treatment options in irritable bowel syndrome," NeuroGastroenterology and Motility: The Official Journal of the European Gastrointestinal Motility Society, vol. 32, no. 8, Article ID e13951, 2020.

[11] P. R. Gibson, E. P. Halmos, and J. G. Muir, "Review article: FODMAPS, prebiotics and gut health-the FODMAP hypothesis revisited," Alimentary Pharmacology \& Therapeutics, vol. 52, no. 2, pp. 233-246, 2020.

[12] C. Meydan, E. Afshinnekoo, N. Rickard et al., "Improved gastrointestinal health for irritable bowel syndrome with 
metagenome-guided interventions," Precision Clinical Medicine, vol. 3, no. 2, pp. 136-146, 2020.

[13] I. A. Hujoel, "Nutritional status in irritable bowel syndrome: a North American population-based study," JGH Open, vol. 4, no. 4, pp. 656-662, 2020.

[14] C. J. Black, Y. Yuan, C. P. Selinger et al., "Efficacy of soluble fibre, antispasmodic drugs, and gut-brain neuromodulators in irritable bowel syndrome: a systematic review and network meta-analysis," The Lancet Gastroenterology \& Hepatology, vol. 5, no. 2, pp. 117-131, 2020.

[15] N. Alammar, L. Wang, B. Saberi et al., "The impact of peppermint oil on the irritable bowel syndrome: a meta-analysis of the pooled clinical data," BMC Complementary and Alternative Medicine, vol. 19, no. 1, p. 21, 2019.

[16] B. Ahluwalia, M. K. Magnusson, L Böhn et al., "Randomized clinical trial: effects of Aloe barbadensis Mill. extract on symptoms, fecal microbiota and fecal metabolite profiles in patients with irritable bowel syndrome," Neuro-Gastroenterology and Motility: The Official Journal of the European Gastrointestinal Motility Society, vol. 32, no. 8, Article ID e13860, 2020.

[17] F. Azpiroz, L. Molne, S. Mendez et al., "Effect of chicoryderived inulin on abdominal sensations and bowel motor function," Journal of Clinical Gastroenterology, vol. 51, no. 7, pp. 619-625, 2017.

[18] K. Davis, S. Philpott, D. Kumar, and M. Mendall, "Randomised double-blind placebo-controlled trial of aloe vera for irritable bowel syndrome," International Journal of Clinical Practice, vol. 60, no. 9, pp. 1080-1086, 2006.

[19] S. W. Hong, J. Chun, S. Park, H. J. Lee, J. P. Im, and J. S. Kim, "Aloe vera is effective and safe in short-term treatment of irritable bowel syndrome: a systematic review and metaanalysis," Journal of Neurogastroenterology and Motility, vol. 24, no. 4, pp. 528-535, 2018.

[20] Z. Z. R. M. Weerts, A. A. M. Masclee, B. J. M. Witteman et al., "Efficacy and safety of peppermint oil in a randomized, double-blind trial of patients with irritable bowel syndrome," Gastroenterology, vol. 158, no. 1, pp. 123-136, 2020.

[21] B. Zöller, H. Ohlsson, R. Waehrens, J. Sundquist, and K. Sundquist, "Association of irritable bowel syndrome and venous thromboembolism," Scandinavian Journal of Gastroenterology, vol. 53, no. 7, pp. 784-789, 2018.

[22] J. Gregson, S. Kaptoge, T. Bolton et al., "Cardiovascular risk factors associated with venous thromboembolism," JAMA Cardiology, vol. 4, no. 2, pp. 163-173, 2019.

[23] L. P. Svetkey, D. Simons-Morton, W. M. Vollmer et al., "Effects of dietary patterns on blood pressure," Archives of Internal Medicine, vol. 159, no. 3, pp. 285-293, 1999.

[24] L. J. Appel, T. J. Moore, E. Obarzanek et al., "A clinical trial of the effects of dietary patterns on blood pressure," New England Journal of Medicine, vol. 336, no. 16, pp. 1117-1124, 1997.

[25] T. T. Fung, M. L. McCullough, P. Newby et al., "Diet-quality scores and plasma concentrations of markers of inflammation and endothelial dysfunction," The American Journal of Clinical Nutrition, vol. 82, no. 1, pp. 163-173, 2005.

[26] R. J. de Souza, J. F. Swain, L. J. Appel, and F. M. Sacks, "Alternatives for macronutrient intake and chronic disease: a comparison of the OmniHeart diets with popular diets and with dietary recommendations," The American Journal of Clinical Nutrition, vol. 88, no. 1, pp. 1-11, 2008.

[27] R. E. Casiday, A. P. Hungin, C. S. Cornford, N. J. De Wit, and M. T. Blell, "Patients' explanatory models for irritable bowel syndrome: symptoms and treatment more important than explaining aetiology," Family Practice, vol. 26, no. 1, pp. 40-47, 2009.

[28] Y. He, R. Xu, W. Wang, J. Zhang, and X. Hu, "Probiotics, prebiotics, antibiotic, Chinese herbal medicine, and fecal microbiota transplantation in irritable bowel syndrome," Medicine, vol. 99, no. 32, Article ID e21502, 2020.

[29] M. Bernardi, A. L. Fedullo, E. Bernardi et al., "Diet in neurogenic bowel management: a viewpoint on spinal cord injury," World Journal of Gastroenterology, vol. 26, no. 20, pp. 2479-2497, 2020.

[30] G. Shi, H. Jiang, J. Feng et al., "Aloe vera mitigates dextran sulfate sodium-induced rat ulcerative colitis by potentiating colon mucus barrier," Journal of Ethnopharmacology, vol. 279, Article ID 114108, 2021.

[31] H. Khedmat, A. Karbasi, M. Amini, A. Aghaei, and S. Taheri, "Aloe vera in treatment of refractory irritable bowel syndrome: trial on Iranian patients," Journal of Research in Medical Sciences: The Official Journal of Isfahan University of Medical Sciences, vol. 18, no. 8, p. 732, 2013.

[32] F. C. Cadona, D. V. De Souza, T. Fontana et al., "Acai (Euterpe oleracea mart.) as a potential anti-neuroinflammatory agent: NLRP3 priming and activating signal pathway modulation," Molecular Neurobiology, 2021.

[33] R. Costa, D. Azevedo, P. Barata, R. Soares, L. F. Guido, and D. O. Carvalho, "Antiangiogenic and antioxidant in vitro properties of hydroethanolic extract from acai (Euterpe oleracea) dietary powder supplement," Molecules, vol. 26, no. 7, 2021.

[34] S. L. Baptista, C. L. K. Copetti, A. L. Cardoso, and P. F. Di Pietro, "Biological activities of acai (Euterpe oleracea Mart.) and jucara (Euterpe edulis Mart.) intake in humans: an integrative review of clinical trials," Nutrition Reviews, 2021.

[35] S. I. B. M. Terrazas, B. S. M. Galan, F. G. De Carvalho et al., "Açai pulp supplementation as a nutritional strategy to prevent oxidative damage, improve oxidative status, and modulate blood lactate of male cyclists," European Journal of Nutrition, vol. 59, no. 7, pp. 2985-2995, 2020.

[36] G. F. De Bem, A. Okinga, D. T. Ognibene et al., "Anxiolytic and antioxidant effects of Euterpe oleracea Mart. (açaí) seed extract in adult rat offspring submitted to periodic maternal separation," Applied Physiology Nutrition and Metabolism, vol. 45, no. 11, pp. 1277-1286, 2020.

[37] B. J. Cury, T. Boeing, L. B. Somensi et al., "Açaí berries (Euterpe oleracea Mart.) dried extract improves ethanol-induced ulcer in rats," Journal of Pharmacy and Pharmacology, vol. 72, no. 9, pp. 1239-1244, 2020.

[38] C. E. D. S. Monteiro, H. B. D. C. Filho, F. G. O. Silva et al., "Euterpe oleracea Mart. (Açaí) attenuates experimental colitis in rats: involvement of TLR4/COX-2/NF-кB," Inflammopharmacology, vol. 29, no. 1, pp. 193-204, 2021.

[39] T. A. F. M. Magalhães, M. O. D. Souza, S. V. Gomes et al., "Açaí (Euterpe oleracea martius) promotes jejunal tissue regeneration by enhancing antioxidant response in 5-fluorouracil-induced mucositis," Nutrition and Cancer, vol. 73, no. 3, pp. 523-533, 2021.

[40] V. C. B. Pontes, J. P. T. D. M. Tavares, T. R. Rosenstock et al., "Increased acute blood flow induced by the aqueous extract of Euterpe oleracea Mart. fruit pulp in rats in vivo is not related to the direct activation of endothelial cells," Journal of Ethnopharmacology, vol. 271, Article ID 113885, 2021.

[41] M. S. Fernandes, A. K. Machado, A. K. Machado et al., "Açaí (Euterpe oleracea Mart.) reduces the inflammatory response triggered in vitro by the antipsychotic drug olanzapine in 
RAW 264.7 macrophage cells," Acta Scientiarum Polonorum Technologia Alimentaria, vol. 20, no. 2, pp. 149-163, 2021.

[42] P. O. Barbosa, M. O. Souza, M. P. S. Silva et al., "Açaí (Euterpe oleracea Martius) supplementation improves oxidative stress biomarkers in liver tissue of dams fed a high-fat diet and increases antioxidant enzymes' gene expression in offspring," Biomedicine \& Pharmacotherapy, vol. 139, Article ID 111627, 2021.

[43] M. Camilleri, "What is the leaky gut? clinical considerations in humans," Current Opinion in Clinical Nutrition and Metabolic Care, vol. 24, no. 5, pp. 473-482, 2021.

[44] M. Wang, H. Zhao, X. Wen, C. T. Ho, and S. Li, "Citrus flavonoids and the intestinal barrier: interactions and effects," Comprehensive Reviews in Food Science and Food Safety, vol. 20, no. 1, pp. 225-251, 2021.

[45] S. Chen, J. Jiang, G. Chao, X. Hong, H. Cao, and S. Zhang, "Pure total flavonoids from citrus protect against nonsteroidal anti-inflammatory drug-induced small intestine injury by promoting autophagy in vivo and in vitro," Frontiers in Pharmacology, vol. 12, Article ID 622744, 2021.

[46] J. D. S. Carvalho, D. Ramadan, V. De Paiva Gonçalves et al., "Impact of citrus flavonoid supplementation on inflammation in lipopolysaccharide-induced periodontal disease in mice," Food \& Function, vol. 12, no. 11, pp. 5007-5017, 2021.

[47] B. He, J. Jiang, Z. Shi et al., "Pure total flavonoids from citrus attenuate non-alcoholic steatohepatitis via regulating the gut microbiota and bile acid metabolism in mice," Biomedicine \& Pharmacotherapy, vol. 135, Article ID 111183, 2021.

[48] S. Alghamdi, "Antinociceptive effect of the citrus flavonoid eriocitrinon postoperative pain conditions," Journal of Pain Research, vol. 13, pp. 805-815, 2020.

[49] S. Raimondo, D. Nikolic, A. Conigliaro et al., "Preliminary results of CitraVes ${ }^{\mathrm{TM}}$ effects on low density lipoprotein cholesterol and waist circumference in healthy subjects after 12 Weeks: a pilot open-label study," Metabolites, vol. 11, no. 5, pp. 1-14, 2021.

[50] D. Victoria-Montesinos, M. S. Abellan Ruiz, A. J. Luque Rubia et al., "Effectiveness of consumption of a combination of citrus fruit flavonoids and olive leaf polyphenols to reduce oxidation of low-density lipoprotein in treatment-naive cardiovascular risk subjects: a randomized double-blind controlled study," Antioxidants, vol. 10, no. 4, p. 589, 2021.

[51] G. Liamis, E. Liberopoulos, G. Alexandridis, and M. Elisaf, "Hypomagnesemia in a department of internal medicine," Magnesium Research, vol. 25, no. 4, pp. 149-158, 2012.

[52] G. Winther, B. M. Pyndt Jørgensen, B. Elfving et al., "Dietary magnesium deficiency alters gut microbiota and leads to depressive-like behaviour," Acta Neuropsychiatrica, vol. 27, no. 3, pp. 168-176, 2015.

[53] W. Tan, D.-C. Qian, M.-M. Zheng, X. Lu, Y. Han, and D.-Y. Qi, "Effects of different doses of magnesium sulfate on pneumoperitoneum-related hemodynamic changes in patients undergoing gastrointestinal laparoscopy: a randomized, double-blind, controlled trial," BMC Anesthesiology, vol. 19, no. 1, p. 237, 2019.

[54] G. Manes, A. Repici, and C. Hassan, "Randomized controlled trial comparing efficacy and acceptability of split- and standard-dose sodium picosulfate plus magnesium citrate for bowel cleansing prior to colonoscopy," Endoscopy, vol. 46, no. 8, pp. 662-669, 2014.

[55] H. Mohammadi, A. Shamshirian, S. Eslami, D. Shamshirian, and M. A. Ebrahimzadeh, "Magnesium sulfate attenuates lethality and oxidative damage induced by different models of hypoxia in mice," BioMed Research International, vol. 2020, Article ID 2624734, , 2020.

[56] E. O. Adewoye and A. O. Ige, "Effect of magnesium on gastrointestinal transit time in normal and diabetic rats: possible mechanism of action," African Journal of Medicine and Medical Sciences, vol. 41, no. 4, pp. 373-378, 2012.

[57] J. Ludden, J. Flexner, and I. Wright, "Studies on ascorbic acid deficiency in Gastric diseases: incidence, diagnosis and treatment," American Journal of Digestive Diseases, vol. 8, pp. 249-252, 1941.

[58] V. M. Crescenzo and D. Cayer, "Plasma vitamin C levels in patients with peptic ulcer; response to oral load test of ascorbic acid," Gastroenterology, vol. 8, no. 6, pp. 754-761, 1947.

[59] Y. Ohta, S. Chiba, Y. Imai, Y. Kamiya, T. Arisawa, and A. Kitagawa, "Ascorbic acid deficiency aggravates stress-induced gastric mucosal lesions in genetically scorbutic ODS rats," Inflammopharmacology, vol. 14, no. 5-6, pp. 231-235, 2006.

[60] A. Aditi and D. Y. Graham, "Vitamin C, gastritis, and gastric disease: a historical review and update," Digestive Diseases and Sciences, vol. 57, no. 10, pp. 2504-2515, 2012.

[61] S. Mousavi, U. Escher, E. Thunhorst et al., "Vitamin C alleviates acute enterocolitis in Campylobacter jejuni infected mice," Scientific Reports, vol. 10, no. 1, p. 2921, 2020.

[62] H. A. Hutchings, K. Wareham, J. N. Baxter et al., "A randomised, cross-over, placebo-controlled study of aloe vera in patients with irritable bowel syndrome: effects on patient quality of life," ISRN gastroenterology, vol. 2011, Article ID 206103, 2011.

[63] S. Storsrud, I. Ponten, and M. Simren, "A pilot study of the effect of Aloe Barbadensis mill. extract (AVH200(R)) in patients with irritable bowel syndrome: a randomized, doubleblind, placebo-controlled study," Journal of Gastrointestinal and Liver Diseases, vol. 24, no. 3, pp. 275-280, 2015.

[64] E. Eypasch, J. I. Williams, S. Wood-Dauphinee et al., "Gastrointestinal quality of life index: development, validation and application of a new instrument," British Journal of Surgery, vol. 82, no. 2, pp. 216-222, 1995.

[65] H.-H. Lien, C.-C. Huang, P.-C. Wang et al., "Validation assessment of the Chinese (Taiwan) version of the gastrointestinal quality of life index for patients with symptomatic gallstone disease," Journal of Laparoendoscopic \& Advanced Surgical Techniques, vol. 17, no. 4, pp. 429-434, 2007.

[66] C. N. Bernstein, "Editorial: the impact of the placebo effect in Crohn's disease," Alimentary Pharmacology \& Therapeutics, vol. 45, no. 11, pp. 1471-1472, 2017.

[67] S. Elsenbruch and P. Enck, "Placebo effects and their determinants in gastrointestinal disorders," Nature Reviews Gastroenterology \& Hepatology, vol. 12, no. 8, pp. 472-485, 2015.

[68] M. M. Estevinho, J. Afonso, I. Rosa et al., "Placebo effect on the health-related quality of life of inflammatory bowel disease patients: a systematic review with meta-analysis," Journal of Crohn's and Colitis, vol. 12, no. 10, pp. 1232-1244, 2018.

[69] V. Jairath, G. Y. Zou, C. E. Parker et al., "Placebo response and remission rates in randomised trials of induction and maintenance therapy for ulcerative colitis," Cochrane Database of Systematic Reviews, vol. 9, no. 9, Article ID CD011572, 2017.

[70] S. Soenen, C. K. Rayner, K. L. Jones, and M. Horowitz, "The ageing gastrointestinal tract," Current Opinion in Clinical Nutrition and Metabolic Care, vol. 19, no. 1, pp. 12-18, 2016.

[71] M. Camilleri, J. S. Lee, B. Viramontes, A. E. Bharucha, and E. G. Tangalos, "Insights into the pathophysiology and 
mechanisms of constipation, irritable bowel syndrome, and diverticulosis in older people," Journal of the American Geriatrics Society, vol. 48, no. 9, pp. 1142-1150, 2000.

[72] A. P. N. Majumdar, R. Jaszewski, and M. A. Dubick, "Effect of aging on the gastrointestinal tract and the pancreas," Experimental Biology and Medicine, vol. 215, no. 2, pp. 134-144, 1997.

[73] K. Kato, T. Odamaki, E. Mitsuyama, H. Sugahara, J.-Z. Xiao, and R. Osawa, "Age-related changes in the composition of gut Bifidobacterium species," Current Microbiology, vol. 74, no. 8, pp. 987-995, 2017.

[74] A. Jena, C. A. Montoya, J. A. Mullaney et al., "Gut-brain axis in the early postnatal years of life: a developmental perspective," Frontiers in Integrative Neuroscience, vol. 14, p. 44, 2020.

[75] Z. Jin, W. Li, W. Wang, and B. Sun, "Complete genome sequence of Bifidobacterium adolescentis ZJ2, isolated from a centenarian in anhui, China," Microbiology resource announcements, vol. 9, no. 29, pp. e00710-e00720, 2020.

[76] C. Sostres, C. Gargallo, and A. Lanas, "Drug-related damage of the ageing gastrointestinal tract," Best Practice \& Research Clinical Gastroenterology, vol. 23, no. 6, pp. 849-860, 2009.

[77] A. L. Stewart, S. Greenfield, R. D. Hays et al., "Functional status and well-being of patients with chronic conditions," Journal of the American Medical Association, vol. 262, no. 7, pp. 907-913, 1989.

[78] P. Czubkowski, M. Osiecki, E. Szymanska, and J. Kierkus, "The risk of cardiovascular complications in inflammatory bowel disease," Clinical and Experimental Medicine, vol. 20, no. 4, pp. 481-491, 2020.

[79] A. Trzeciak-Jedrzejczyk, R. Makosiej, M. Kolejwa, E. Glowacka, and E. Czkwianianc, "The role of adhesion molecules in inflammatory bowel disease in children. Assessment of the possible risk of cardiovascular complications," Przeglad Gastroenterologiczny, vol. 12, no. 3, pp. 181-185, 2017.

[80] R. Schicho, G. Marsche, and M. Storr, "Cardiovascular complications in inflammatory bowel disease," Current Drug Targets, vol. 16, no. 3, pp. 181-188, 2015.

[81] P. Rellecke and B. E. Strauer, "Chronic inflammatory bowel disease and cardiovascular complications," Medizinische Klinik, vol. 101, no. Suppl 1, pp. 56-60, 2006.

[82] S. S. Ahmed, R. C. Gupta, and R. R. Brancato, "Significance of nausea and vomiting during acute myocardial infarction," American Heart Journal, vol. 95, no. 5, pp. 671-672, 1978.

[83] T. Herlihy, M. E. McIvor, C. C. Cummings, C. O. Siu, and M. Alikahn, "Nausea and vomiting during acute myocardial infarction and its relation to infarct size and location," The American Journal of Cardiology, vol. 60, no. 1, pp. 20-22, 1987.

[84] S. Cheung, J. C. Quiwa, A. Pillai, C. Onwu, Z. J. Tharayil, and R. Gupta, "Superior mesenteric artery thrombosis and acute intestinal ischemia as a consequence of COVID-19 infection," The American journal of case reports, vol. 21, Article ID e925753, 2020.

[85] A. Benmassaoud, L. AlRubaiy, D. Yu et al., "A stepwise thrombolysis regimen in the management of acute portal vein thrombosis in patients with evidence of intestinal ischaemia," Alimentary Pharmacology \& Therapeutics, vol. 50, no. 9, pp. 1049-1058, 2019.

[86] M. M. Olson, P. B. Ilada, and K. N. Apelgren, "Portal vein thrombosis," Surgical Endoscopy, vol. 17, no. 8, p. 1322, 2003.

[87] M. Federle, G. Chun, R. Jeffrey, and R. Rayor, "Computed tomographic findings in bowel infarction," American Journal of Roentgenology, vol. 142, no. 1, pp. 91-95, 1984.
[88] T. Der-Silaphet, J. Malysz, S. Hagel, A. Larry Arsenault, and J. D. Huizinga, "Interstitial cells of cajal direct normal propulsive contractile activity in the mouse small intestine," Gastroenterology, vol. 114, no. 4, pp. 724-736, 1998.

[89] Y. Ou, S. J. Gibbons, S. M. Miller et al., "SCN5A is expressed in human jejunal circular smooth muscle cells," Neuro-Gastroenterology and Motility, vol. 14, no. 5, pp. 477-486, 2002.

[90] Y. A. Saito, P. R. Strege, D. J. Tester et al., "Sodium channel mutation in irritable bowel syndrome: evidence for an ion channelopathy," American Journal of Physiology-Gastrointestinal and Liver Physiology, vol. 296, no. 2, pp. G211-G218, 2009.

[91] T. E. Verstraelen, R. M. A. Ter Bekke, P. G. A. Volders, A. A. M. Masclee, and J. W. Kruimel, "The role of theSCN5Aencoded channelopathy in irritable bowel syndrome and other gastrointestinal disorders," Neuro-Gastroenterology and Motility, vol. 27, no. 7, pp. 906-913, 2015.

[92] P. R. Strege, Y. Ou, L. Sha et al., "Sodium current in human intestinal interstitial cells of Cajal," American Journal of Physiology-Gastrointestinal and Liver Physiology, vol. 285, no. 6, pp. G1111-G1121, 2003.

[93] P. R. Strege, A. Mazzone, C. E. Bernard et al., "Irritable bowel syndrome patients have SCN5A channelopathies that lead to decreased NaV1.5 current and mechanosensitivity," American Journal of Physiology-Gastrointestinal and Liver Physiology, vol. 314, no. 4, pp. G494-G503, 2018.

[94] M. D. Coates, K. E. Vrana, and V. Ruiz-Velasco, "The influence of voltage-gated sodium channels on human gastrointestinal nociception," Neuro-Gastroenterology and Motility, vol. 31, no. 2, Article ID e13460, 2019.

[95] A. Beyder, A. Mazzone, P. R. Strege et al., "Loss-of-function of the voltage-gated sodium channel NaV1.5 (channelopathies) in patients with irritable bowel syndrome," Gastroenterology, vol. 146, no. 7, pp. 1659-1668, 2014.

[96] G. R. Locke 3rd, M. J. Ackerman, A. R. Zinsmeister, P. Thapa, and G. Farrugia, "Gastrointestinal symptoms in families of patients with an SCN5A-encoded cardiac channelopathy: evidence of an intestinal channelopathy," The American Journal of Gastroenterology, vol. 101, no. 6, pp. 1299-1304, 2006.

[97] J. Tfelt-Hansen, B. G. Winkel, M. Grunnet, and T. Jespersen, "Inherited cardiac diseases caused by mutations in the Nav1.5 sodium channel," Journal of Cardiovascular Electrophysiology, vol. 21, no. 1, pp. 107-115, 2010.

[98] J. D. Kapplinger, D. J. Tester, M. Alders et al., “An international compendium of mutations in the SCN5A-encoded cardiac sodium channel in patients referred for Brugada syndrome genetic testing," Heart Rhythm, vol. 7, no. 1, pp. 33-46, 2010.

[99] C. R. Bezzina, J. Barc, Y. Mizusawa et al., "Common variants at SCN5A-SCN10A and HEY2 are associated with Brugada syndrome, a rare disease with high risk of sudden cardiac death," Nature Genetics, vol. 45, no. 9, pp. 1044-1049, 2013. 